MIRKA MESQUITA \& KARLA PATRÍCIA HOLANDA MARTINS

\section{Mirka Mesquita}

Université de Bretagne Occidentale (UBOBrest), professora (ATER) do Departamento de Psicologia (CRPC-

CLCS), Brest, França.

Karla Patrícia Holanda Martins

Universidade Federal do Ceará (UFC), professora do Departamento de Psicologia, cordenadora do Programa de PósGraduação em Psicologia, Fortaleza/CE, Brasil.
RESUMO: A peculiaridade do funcionamento de Bonneuil no tratamento do autismo constitui o objeto central de investigação do presente artigo. Busca-se compreender como o "estouro" dessa instituição, caracterizado pelas oscilações frequentes de estadias e de profissionais, pode contribuir para o desenvolvimento psíquico dos autistas. Este estudo baseia-se no método clínico e referencial psicanalítico, a partir de observação participante durante um estágio realizado na Escola de Bonneuil. Defende-se a pertinência desse dispositivo, cujo alicerce principal é o reconhecimento da criança como sujeito em devenir. Neste caso, é possível arriscar efeitos subjetivantes através do imprevisto.

Palavras-chave: psicanálise; Bonneuil; instituição estourada; autismo; tratamento.

Abstract: Bonneuil School: study about the "burst" treatment of autism. The peculiarity of Bonneuil in the treatment of autism is the central object of investigation of this article. We seek to understand how the "burst" functioning of Bonneuil, characterized by the frequent alternation of stays and professionals, can contribute to the mental development of these children. This study is based on the clinical and psychoanalytic methods, as experienced through participant observation in a trainee program at Bonneuil. We defend the pertinence of the device whose main foundation is the recognition of the child as a subject-to-be. In this case, it's possible to risk effects of subjectivity through the unforeseen.

Keywords: psychoanalysis; Bonneuil; burst institution; autism; treatment.

DOI - http://dx.doi.org/10.1590/1809-44142018001006 
A té o fim do século XX, podíamos testemunhar sobre o lugar de exclusão no qual eram postas crianças que apresentavam desarmonias do desenvolvimento. Os entraves mais relevantes eram detectados frequentemente nos primeiros anos de integração ao sistema escolar. Outros, menos ostensivos, eram identificados somente num momento mais avançado do processo de aprendizagem. Na falta de um acompanhamento especializado, as instituições escolares se viam obrigadas a assinalar tais dificuldades e a recusar uma vaga para estas crianças, em nome de uma inaceitável inadaptação social. Afastadas do sistema educacional preconizado aos demais, tais crianças eram, pouco a pouco, excluídas da sociedade. Rotuladas como "doen

tes mentais", vulgarmente "crianças loucas", eram encaminhadas a instituições de tratamento, sendo oprimidas pelo peso de diagnósticos graves que lhes marcavam como sentenças (DUCHÉ, 1990; HOCHMANN, 2009; LOBO, 2008).

Nas últimas décadas, houve um avanço notável no processo de humanização do tratamento de crianças com sofrimento psíquico, resultado da determinação e do esforço permanentes de profissionais dedicados a essa causa. Relembra-se aqui particularmente a contribuição do trabalho realizado por Maud Mannoni, cuja obstinação fundou um novo olhar sobre a criança doente mental e o seu espaço na sociedade. Com a emergência do movimento antipsiquiátrico, no final dos anos 1960, o pensamento desta psicanalista francesa ganhou bastante visibilidade, tendo repercussões iniciais na França e estendendo-se, posteriormente, para vários países onde a psicanálise fora difundida. Ao articular os ideais da antipsiquiatria aos ensinamentos de Lacan, Mannoni elaborou uma densa crítica ao poder psiquiátrico e aos lugares que realizavam uma acolhida inadaptada do sofrimento psíquico infantil (1964/1981, 1967/1971, 1970/1989).

Seu discurso se vinculou em seguida à prática institucional, a partir da qual ela criou, em 1969, com o psicanalista Robert Lefort e outros colaboradores, a Escola Experimental de Bonneuil (localizada na cidade Bonneuil-sur-Marne, no sul de Paris). Representando a consolidação de ideais notáveis, há 46 anos esta escola acolhe, com a mesma sensibilidade e engajamento, crianças com graves entraves no desenvolvimento psíquico, excluídas do sistema escolar. Instituição mítica, Bonneuil já atraiu, ao longo dos seus anos de existência, um número importante de pesquisadores e profissionais, brasileiros e estrangeiros (BERNARDINO, 1998; KUPFER, 1998; de LAJONQUIÈRE, 1998; GEOFFROY, 2004; VANIER, 2004). No entanto, a fertilidade das questões oriundas do seu funcionamento "sem moldes" permanecem inesgotáveis.

Sustentada por uma base institucional singular, Bonneuil propõe um "estouro" institucional, onde vaivéns constantes são necessários a fim de impedir o engessamento da instituição e o aprisionamento dessas crianças num sistema asilar. 0 imprevisto representa assim uma importante ferramenta terapêutica que fundamenta esta prática. Independente de diagnósticos, todas as crianças são convidadas a vivenciar uma experiência subjetiva, que consiste em "se perder" para "se encontrar" como sujeito do seu próprio desejo (MANNONI, 1973/1977, 1976).

No variado grupo de crianças de Bonneuil, nós encontramos uma prevalência considerável de autistas. Estes, como os demais, são lançados no "estouro" institucional (MANNONI, 1976). No entanto, estudos apontam importantes particularidades desse transtorno do desenvolvimento, reconhecendo-o como um quadro clínico diferente da psicose infantil (KANNER, 1943; LEFORT, 2003; MESQUITA, 2012). Dentre suas principais características, vale ressaltar a necessidade marcante de imutabilidade, já destacada por Léo Kanner, em 1956. Ao supor que as ínfimas mudanças ambientais podem provocar reações desmesuradas nos autistas, muitos profissionais optam atualmente por tratamentos inspirados numa organização pragmática e rotineira do meio ambiente no qual a criança se encontra inserida. Neste contexto, imprevisto e imutabilidade aparecem como elementos inconciliáveis.

A peculiaridade do funcionamento de Bonneuil no tratamento de crianças autistas constitui o objeto central de investigação do presente artigo. Busca-se compreender como o "estouro" da instituição, com suas oscilações de estadias e sucessões de profissionais, pode contribuir para o desenvolvimento psíquico dessas 


\section{Escola de Bonneuil: estudo sobre o tratamento "estourado" do autismo}

crianças. O presente estudo baseia-se no método clínico e referencial psicanalítico, a partir de observação participante durante um estágio realizado pela autora na Escola de Bonneuil.

\section{AS ESTRATÉGIAS TERAPÊUTICAS DE BONNEUIL}

A excentricidade do projeto de Mannoni chocou-se, desde o início, com o modelo institucional tradicional francês. Para conquistar uma legitimidade institucional, ela precisou enfrentar várias batalhas e resistir aos mais diversos obstáculos de ordem prática, financeira e/ou ideológica (MANNONI, 1973/1977, 1976, 1986). Tendo obtido tal reconhecimento, ela preconizou ainda certa vigilância à possibilidade de engessamento do funcionamento de Bonneuil nas tramas administrativas do sistema de saúde pública, lançando um importante questionamento sobre o assunto: "Até onde podemos sustentar um compromisso com as obrigações administrativas sem correr o risco de perder a razão de ser de um trabalho que só tem sentido se apoiado no desejo de criação e num contínuo questionamento de si?" (MANNONI, 1986, p. 11, tradução das autoras).

Recentemente, Bonneuil atravessou mais uma crise diante da possibilidade de ser fundida a uma outra associação por interesses econômicos do Estado. Nesta proposição, nenhuma convenção escrita garantia à equipe de Bonneuil a conservação das orientações fundadoras propostas por Mannoni. Plantet (2012) lembra que a equipe luta para vencer mais essa batalha, mas sempre carregando em mente o profundo desejo de Mannoni de preferir um fim digno para Bonneuil a uma aceitação tácita de imposições administrativas que a desnaturalizariam. Como pressupostos fundamentais, destacam-se a inclusão social, a antinosografia e o "estouro" institucional.

\section{A INCLUSÃO SOCIAL}

O termo escola não foi atrelado ao nome de Bonneuil por acaso. Esta foi uma das mais importantes conquistas de Mannoni. Segundo ela, este significante ganha forma de estratégia terapêutica uma vez que, como todas as outras crianças, as de Bonneuil também passam suas jornadas diárias na escola. Lá, elas recebem uma instrução escolar cujo nível varia de acordo com o potencial de cada uma, provocando nelas um sentimento de integração social. Além da proposta educativa, Bonneuil oferece também uma acolhida terapêutica.

Mannoni (1964/1981, 1967/1971) considerava a criança portadora de uma doença mental como a representante de um "aprisionamento psíquico" no discurso familiar e, sobretudo, no fantasma parental. Para "libertá-la", era preciso provocar uma separação física e psíquica, a partir da qual ela poderia abdicar da identificação absoluta ao Outro alienante. Para isso, a criança precisava ser inserida num espaço onde o seu discurso aparecesse livre dos entraves familiares e sociais que impediam a loucura de se manifestar. Um espaço onde pudesse contar, ela mesma, sua própria história. Jacques, ex-aluno de Bonneuil, nos deixa seu testemunho:

Digamos que aqui a vantagem é que nós podemos falar livremente. Na sociedade, as pessoas têm uma mentalidade estreita; nós não podemos dizer o que pensamos. As pessoas dizem: "Queremos que os loucos vivam como nós". Mas, se eles são loucos, é justamente porque o estilo de vida de pessoas normais não lhes agrada. (MANNONI, 1976, p. 28, tradução das autoras)

A aceitação incondicional da loucura devia ser colocada em prática e, para a sua radicalidade, Mannoni preconizava um duplo trabalho: num sentido, buscava-se reintegrar essas crianças na sociedade, mostrandoIhes que, para tal desafio, era preciso abrir mão de um gozo absoluto e aceitar as restrições impostas pelo grupo social; no outro sentido, pretendia conscientizar a sociedade sobre as dificuldades dessas crianças, a fim de alcançar uma melhor aceitação social da doença mental infantil. Mannoni propunha uma subversão de valores sobre a loucura, elemento essencial à realização de um encontro legítimo entre os profissionais e as crianças de Bonneuil. 
A luta contra a exclusão social de crianças doentes mentais tornou-se, assim, o objetivo maior desta equipe. A ideia era inovadora na época e sua relevância foi reconhecida não só por profissionais da educação e da saúde mental, mas também pelo Estado, formando as bases das políticas públicas atuais de educação inclusiva.

\section{O “ESTOURO” INSTITUCIONAL}

Apoiada nessas ideias, Mannoni inscreveu-se numa ideologia antimanicomial e questionou o funcionamento convencional de instituições de tratamento que se opunham a toda forma de reciclagem de suas práticas. $O$ perigo de tal engessamento institucional foi assim descrito por Robert Lefort:

Uma instituição é como uma pessoa que se nutre de outras que estão sob seus cuidados [...] e, em nenhum momento, o sujeito consegue se separar dela sem correr o risco de "estourar". Uma instituição que se diz diferente é aquela que, num efeito de balança, toma o "estouro" em consideração e permite ao sujeito se situar no mesmo nível da palavra, dando a ele a possibilidade de se separar, de produzir um corte com a instituição. (MANNONI, 1976, p. 48, tradução das autoras)

Ao contrário do que acontece na maioria das grandes instituições, as críticas são bem recebidas pela equipe de Bonneuil. Esta abertura aos olhares exteriores mantém vivo o espírito ideológico que sustenta a célebre noção de instituição estourada. O termo experimental, atrelado ao nome da escola, traz em si esta ideia. No entanto, este termo é, muitas vezes, interpretado erroneamente, fazendo emergir confabulações de que experimentos científicos são feitos com crianças a fim de investigar mais profundamente a doença mental infantil.

Quem conheceu e vivenciou o funcionamento de Bonneuil sabe bem que não é isso que acontece no interior dos seus muros. Ao contrário, esta instituição foi idealizada como um lugar de vida, isto é, "um lugar onde as pessoas não se interrogam mais sobre o que é a doença mental, sobre o que é ser uma criança superdotada ou retardada, não se sabe mais quem é louco e quem não é" (MANNONI, 1976, p. 21, tradução das autoras). E o termo experimental, como define Mannoni, "deve ser entendido no sentido de que Bonneuil não é o lugar de aplicação de uma regulamentação tradicional, mas sim um lugar onde algo a mais pode acontecer a partir do espaço vazio deixado ao imprevisto" (ibidem, p. 54, tradução das autoras).

Segundo a psicanalista, é o próprio imprevisto, o inesperado vivido a partir dos encontros mundanos, que inscreve marcas na criança, fazendo-a avançar na sua conquista pelo desejo. Os espaços de alternâncias funcionam como cortes ou escansões do discurso, onde o guia é a própria criança. Diante de uma avalanche de demandas, a equipe de profissionais mantém o papel fundamental de transformar necessidade em desejo. $O$ adulto a quem a criança encontra-se vinculada a apoiará até que esta possa elaborar novos encontros, descobrindo outros marcos (pessoas ou lugares) que Ihe transmitam confiança e com os quais ela poderá estabelecer novos laços. Quando a presença deste adulto torna-se ausência, a criança descobre que, nesse sistema de substituições, ela não poderá nunca mais encontrar outro substituto adequado ao objeto originalmente perdido. Nessa oscilação entre "aqui e ali" é inserido "um espaço significante em que a criança é levada a perder-se para lhe propiciar a ilusão de renascer aí, sustentando-se como sujeito pelo jogo de escansão presença-ausência" (MANNONI, 1973/1977, p. 73). Acredita-se que é na ocasião de uma separação bem-sucedida que a criança torna-se sujeito do seu desejo.

Logo, os espaços de oscilação oferecidos no quadro institucional de Bonneuil têm por função operar tais separações através de aberturas para o mundo exterior, concretizadas pelas viagens de férias escolares com a equipe, pelas estadias em famílias de acolhida em diversas regiões da França, pelo trabalho realizado na padaria da esquina ou na oficina mecânica do bairro, numa loja de roupas ou num petshop etc. Entende-se que a instituição deve permanecer como um lugar de acolhida, onde a criança sabe que pode voltar sempre que sentir a necessidade de um reconforto. No entanto, ela deve guardar em mente que é do lado de fora que acontece o essencial da vida (MANNONI, 1973/1977). 


\section{Escola de Bonneuil: estudo sobre o tratamento "estourado" do autismo}

\section{A ANTINOSOGRAFIA}

Nos estudos de Mannoni, as diferentes estruturas não são especificadas e nem obedecem a referenciais psiquiátricos. Em Bonneuil, também não se faz nenhuma distinção estrutural das crianças. A psicanalista considera que é preciso abster-se do diagnóstico e enxergar o indivíduo com suas potencialidades a fim de colocar em movimento aquilo que essas etiquetas psiquiátricas cristalizam no sujeito, provocando sua exclusão e dessubjetivação. Os conhecimentos elaborados sobre a criança e sua história de vida devem ser inscritos no contexto institucional, a partir daquilo que ela traz consigo ou do que os pais acrescentam nas reuniões (MANNONI, 1973/1977).

Vanier (2004) lembra que esta questão era essencial para Mannoni, porém não decisiva, pois a psicose possui uma estrutura que não pode ser reduzida unicamente à sua designação. $\mathrm{O}$ autor aponta ainda a influência da psicanálise que defende a possibilidade de oferecer à criança com sofrimento psíquico uma experiência de subjetividade, ou seja, de proporcionar a emergência de um sujeito capaz de interrogar-se sobre o que ele deseja, independente de seus diagnósticos. Tal pensamento gerou vivas interlocuções com a antipsiquiatria.

No entanto, Mannoni (1970/1989) já havia constatado as dificuldades de introduzir a prática psicanalítica nas instituições - sobretudo com crianças doentes mentais - por duas razões: de um lado, o discurso liberado pela cura não é sempre bem aceito pela instituição; de outro, o paciente pode tomar o analista como suspeito de uma cumplicidade com as forças repressivas que o aprisionam. Todavia, ela propôs pautar toda a organização institucional de Bonneuil nesta teoria. A proposta era subversiva, como ela mesma explica: "O paradoxo de Bonneuil é que não se pratica aí a psicanálise; mas tudo o que aí se faz baseia-se rigorosamente na psicanálise, à qual não se recorre como técnica de ajustamento, mas, outrossim, como subversão de um saber e de uma praxis" (MANNONI, 1973/1977, p. 16).

É a ação subversiva da psicanálise que permite à equipe de Bonneuil questionar os moldes psiquiátricos e a ação devastadora de seus significantes. É desta forma que ela escapa do estatuto de estabelecimento de tratamento para existir como um lugar de vida.

\section{É POSSÍVEL FALAR DE TRATAMENTO “ESTOURADO” DO AUTISMO?}

Dentre os entraves psíquicos apresentados pelas crianças de Bonneuil, nós podemos encontrar um número considerável de autistas. Estes, assim como os demais, vivem a experiência do "estouro" institucional.

Além do ideal de antinosografia, outro fator relevante da época respaldou essa não segregação. Nos anos 70, o autismo ainda não tinha sido completamente dissociado do grupo das psicoses infantis, nem para os psiquiatras (APA, 1972), nem para os psicanalistas (BETTELHEIM, 1967/1987; KLEIN, 1930/1966; LACAN, 19531954/1983; WINNICOTT, 1968). Ora, sabe-se que o conhecimento em torno da clínica do autismo progrediu bastante nos últimos anos, mostrando que este quadro clínico se distancia cada vez mais daquilo que antes era considerado uma psicose infantil. O trabalho realizado por Léo Kanner $(1943,1958)$ representou um marco para a aparição e a evolução do conceito de autismo. A terceira versão do DSM o enquadrou no grupo de transtornos globais do desenvolvimento e extinguiu definitivamente o grupo das psicoses infantis (APA, 1980). Esta dissociação também foi anunciada no campo da psicanálise.

Várias pesquisas recentes sobre os sinais precoces do autismo demonstram que o bebê com risco de autismo já apresenta, desde os primeiros meses de vida, dificuldades aparentes em estabelecer contato com a pessoa que oferece os primeiros cuidados (LAZNIK, 2000, 2006; MAESTRO; MURATORI, 2006). Considera-se que, sem essas trocas, o circuito pulsional mostra-se comprometido desde o início. Baseando-se nos avanços de pesquisas em neurociência, Golse e Delion (2006) concluem que o autismo é o resultado de um problema na interação entre o bebê e o outro materno, ou seja, que sua desordem essencial está associada à sua incapacidade de se relacionar, de atingir, de decifrar e de comunicar seu próprio estado interno. 
Apesar do trabalho iniciado em parceria com Maud Mannoni, Rosine e Robert Lefort (2003) já defendiam a tese de uma diferenciação estrutural para o autismo. Segundo eles, toda construção teórica de uma nova estrutura seria apoiada sobre o fato de que, nos autistas, existe uma falha no primeiro registro de inscrição inconsciente, que resulta na não-existência de uma relação ao Outro. O autista seria confrontado a um Outro ausente que retorna no real, representando uma forma de defesa contra a realidade primária. Os Lefort (2003) afirmavam ainda que, se o significante primordial (S1) não marca o sujeito, o S2 é automaticamente ausente, resultando numa petrificação significante. O autista não se aliena no desejo do Outro e nem sequer estabelece o primeiro laço identificatório, ao contrário da criança psicótica, que estabelece uma relação de gozo ininterrupto.

A recusa do contato visual, auditivo ou mesmo tátil aparece como uma forma de evitar tudo aquilo que venha do Outro, do mundo exterior, ou seja, tudo aquilo que provoca um sentimento de estranheza, vivenciado como invasivo, intrusão intolerável. Para repelir esse movimento ameaçador, o autista busca se proteger num mundo inanimado, onde os imprevistos não são tolerados. Para isso, ele cria um mecanismo de auto-estimulação sensorial, cujos principais sinais são as estereotipias. Assim, o autista permanece preso no seu mundo caótico de sensações que ele tenta controlar (MALEVAL, 2009). A necessidade de imutabilidade ou sameness foi descrita por Kanner (1956) como uma das duas principais características da sintomatologia do autismo, ao lado do isolamento extremo, aloneness. Esses dois sintomas patognômicos ajudaram a melhor definir esse quadro clínico e a inspirar novas formas de tratamento.

Logo, se o objetivo primeiro do tratamento da psicose infantil é realizar uma separação bem sucedida entre os membros da díade e promover a saída da criança do fantasma dos pais, compreende-se que o mesmo tratamento não seria adaptado aos autistas, posto que estes nem atingiram a primeira marca de identificação com o Outro. Segundo Ledoux (1984), alguns profissionais - dentre os quais psicanalistas - denunciam a prática da antinosografia como uma mistura geral entre todas as psicopatologias e consideram que a recusa em estabelecer diagnósticos, encontrando a mesma causa para todas as doenças, resulta em um discurso simplista que impede o bom desenvolvimento da criança. Acrescenta-se ainda o fato de que a psicanálise atravessa uma notável rejeição de pais de crianças autistas, desde os anos 60. Isto se deve às proposições feitas segundo as quais eles seriam os responsáveis pelos transtornos de seus próprios filhos (POTTER, 1933; BETTELHEIM, 1967/1987). Mesmo mantido o enigma etiológico, desaconselha-se atualmente associar as causas do autismo à responsabilidade parental.

Acompanhando esses avanços, as formas de tratamento do autismo também se singularizaram. Algumas correntes científicas propõem uma adaptação máxima do meio social às particularidades do funcionamento psíquico do autista, norteando o tratamento por métodos educativos centrados na organização pragmática do cotidiano. Schopler, Brehm, Kinsbourn e Reichler (1971) defendem a adaptação de todos os ambientes nos quais a criança autista evolui, a fim de facilitar a compreensão das situações apresentadas no decorrer do dia; fator necessário, segundo eles, ao seu bem-estar. Criado por Schopler e Reichler (1971), o método TEACCH é atualmente reconhecido pela comunidade psiquiátrica internacional como uma intervenção eficaz para todas as desordens do espectro autista (APA, 2013).

Essa tendência atual interroga as práticas antigas: Que tratamento é destinado ao autismo em Bonnueil? O que respalda esse trabalho? Seria ele inadaptado a essa clínica? A partir de uma reflexão téorico-clínica, nós demonstramos de que modo o "estouro" da instituição, com sua antinosografia e oscilações de estadias e profissionais, pode contribuir para o desenvolvimento psíquico de crianças autistas.

\section{CASO MARC: TEM ALGUÉM DO OUTRO LADO DA PAREDE?}

Antes de chegar em Bonneuil, Marc, jovem de 14 anos, passava seus dias em casa. No início, algumas tentativas de inserção institucional foram feitas pela família. Mas, sem bons resultados, os pais tomaram a decisão de que Marc estaria melhor em casa, local protegido, onde ele não seria defrontado à exclusão 


\title{
Escola de Bonneuil: estudo sobre o tratamento "estourado" do autismo
}

destinada às crianças "diferentes". Por insistência de um profissional de Bonneuil que os conhecia, a família arrisca uma última tentativa de trabalho institucional com Marc.

Em Bonneuil, Marc manifesta estereotipias intensas, quase constantes, como, por exemplo, o bater de portas, janelas e paredes. Ele sente necessidade de produzir fortes ruídos em ritmo frenético, emitindo ao mesmo tempo gritos agonizantes. $\mathrm{O}$ barulho vindo de outras crianças o invade e o desespera. Marc grita e protege os ouvidos numa tentativa de evitar que seu corpo entre em colapso. As estereotipias criam nele uma borda protetora contra a estranheza produzida pelas mudanças notáveis entre a casa e a escola, entre o único e o coletivo, entre a solidão e a partilha, entre o interior e o exterior. Suas manifestações são aceitas com bastante tolerância pela equipe, que continua a escutar o que Marc tem a dizer através do seu comportamento.

\begin{abstract}
A terapia negativa consiste a se abster de qualquer intervenção precipitada, permanecendo num primeiro momento a escuta da criança, atento ao seu ritmo. Permanecer a escuta no caso do autismo significa deixá-la viver sem impor a nossa presença. É apenas gradualmente que podemos entrar no seu mundo, depois de ter garantido um espaço no qual ela se sente bem. (MANNONI, 1976, p. 300-301, tradução das autoras)
\end{abstract}

As batidas de portas e de paredes se intensificam. Os profissionais de Bonneuil, sensíveis a esses sinais, perguntam sempre: "Marc, quem você procura atrás da parede?", "Quem você está chamando?", "Nós estamos aqui, do outro lado, ao seu lado. Você pode falar conosco, se você quiser". A equipe acredita ser necessário levar em conta todas as formas de manifestação produzidas pela criança, mesmo aquelas mais barulhentas e difíceis de suportar. Em nenhum momento elas devem ser banalizadas e consideradas como sintomas a serem reduzidos ou eliminados segundo uma concepção fenomênica e pragmática. Essas manifestações devem ser tomadas como sintoma no sentido psicanalítico: outra maneira de dizer algo que não pode ser dito através de palavras.

Assim, Marc é convidado a falar e a transformar essa sensação que invade seu corpo em linguagem. Entende-se que Marc é um sujeito ainda não marcado pela falta, responsável pela produção do desejo, mas a equipe está lá para guiá-lo. As intervenções da equipe o "envolvem" e dão-lhe um "banho de linguagem". É neste momento que se dá espaço para o nascimento de uma psiquê, onde palavras são introduzidas para dar sentido a um comportamento.

Percebe-se que Marc intensifica seus gritos e batidas de portas na presença de adultos. Para a equipe, o som torna-se insuportável e ultrapassa os limites alheios. É preciso então contê-lo, tocá-lo e envolvê-lo de presença. Marc parece aceitar essa contenção e controlar seus impulsos. Ele murmura suavemente, vai embora e volta, minutos depois, num constante recomeço. Percebe-se que um ciclo manifestação-contenção se instala, caracterizando uma não-sustentação notável da inscrição do Outro, como se algo falhasse a cada tentativa e que, por isso, precisaria ser constantemente relançado.

Pouco a pouco, observa-se que algo se inscreve em Marc. Desta vez, esse menino procura, com seu olhar, as outras crianças que estão jogando bola no pátio. Ele vai até a entrada da horta e bate a porta freneticamente por alguns minutos. $\mathrm{O}$ barulho do ferro contra o concreto torna-se insuportável para Marie, que se zanga e joga a bola em Marc. Ele se acalma por alguns minutos e ela retorna ao seu jogo. Minutos depois, ele recomeça os batimentos de porta, olhando-a fixamente. Marie reage. Na terceira vez, inconformada, ela joga a bola para o alto e vai embora dizendo: "Estou farta de você!".

Rapidamente, Marc procura outro foco. Ele vê Jean, que lê uma revista em quadrinhos sentado na escada, corre na sua direção e esmurra a porta que se encontra logo atrás. Assim o faz esperando a reação do colega que parece atento à sua leitura e nem sequer nota sua presença. Quando se dá conta da inércia do colega, Marc para suas batidas e vai embora. Ele percebe que sua forma indireta de chamar a atenção do outro falha, vez por outra. Desta vez, é ele quem se farta e vai embora. 
Esta vinheta clínica nos interroga e nos leva à conclusão de que Marc reconhece de fato a presença do outro, mesmo que seja ainda a um nível sensorial, de uma presença física que o faz sentir o contorno do seu corpo "desmantelado". Ele precisa desse outro para sentir-se contido, vivo, já que a falha dessa sustentação física se passa ainda num nível primário da constituição da subjetividade (LEFORT, 2003). Consciente de suas dificuldades mais profundas, a equipe segue num trabalho em torno da subjetivação. Reflete-se a um projeto pessoal que favoreça essa fase ainda arcaica do desenvolvimento humano. Sendo assim, Marc parece bem adaptado às propostas das oficinas de pintura, jardinagem e escultura, a partir das quais ele canaliza o turbilhão de sensações nas mãos que tocam a terra, a argila ou o pincel. Uma descarga sensorial é criada, anulando as manifestações autísticas. Neste momento, percebe-se que ele responde atentamente às demandas do adulto que o acompanha.

Vale ressaltar que, a essa altura, este menino já está sutilmente inserido no estouro da instituição quando ele faz a transição de um atelier para outro, sendo necessário suportar a presença de profissionais e grupos de crianças diferentes. Marc faz seus vaivéns na escola, este pequeno universo com o qual ele começa a se familiarizar. Isto já representa uma maneira de transitar, encontrar outras pessoas e, cada vez mais, reajustarse às mudanças impostas pela instituição.

Inicialmente, as atividades mais longas pareciam-Ihe insuportáveis, mas Marc sabia que ele sempre podia encontrar a porta de saída. Em Bonneuil, a liberdade acordada às crianças é essencialmente a liberdade de expressão e o respeito por todas as posições de recusa, visto que manifestações desta ordem podem ser consideradas como uma primeira expressão do desejo. A única imposição consiste a respeitar as regras necessárias de bom convívio com os demais membros (MANNONI, 1976).

Alguns meses depois, Marc apresenta um progresso notável. Ele suporta cada vez mais os momentos em coletividade, esmurra menos as paredes e portas e seus gritos ecoam mais raramente. Agora, ele procura diretamente outras crianças no pátio, o que nos dá a impressão de que Marc brinca com elas. Ele corre, ri, dirige-se aos colegas, de vez em quando, chamando-os pelo nome. Mesmo limitado, seu contato com os outros parece carregado de expressão. Algumas crianças causam-lhe impulsos mais específicos, como Julien, com quem ele brinca na tentativa de tocar seu nariz. Julien se zanga e o insulta: "Seu idiota, deixe-me em paz!". Isso provoca risos em Marc, que sai de cena tocando seu próprio nariz. Neste momento, percebemos que Marc dá sinais de um prazer compartilhado com outro. Podemos falar de um jogo de descoberta de uma alteridade onde ele precisa tocar seu corpo e em seguida experimentar a sensação que seu comportamento pode produzir no outro, marcas iniciais de operações transitivas (BERGES; BALBO, 2002). Marc busca o toque, não mais de forma passiva como no início, quando ele precisava produzir sons irritantes para chamar o outro a contê-lo. Agora, sua busca é ativa, direta, específica e, pouco a pouco, articulada à linguagem.

Um membro da equipe intervém no grupo de crianças para explicar que Marc usa meios especiais para captar a atenção delas, ressaltando que em Bonneuil é necessário tolerar e respeitar as formas específicas com as quais cada um se expressa. Marc é gradualmente introduzido na roda. Esse menino, cujo destino poderia ter sido "esmagado" pelo peso de uma exclusão social, continua a escrever sua história como um ser singular nesse novo lar de passagem. Agora, Marc se expressa, mostrando à equipe que uma primeira ancoragem psíquica foi alcançada e que sua adaptação ao ambiente escolar foi estabelecida. Assim, um projeto personalizado, singular, levando-o ao encontro com o mundo exterior, que traz imprevistos de outra ordem, torna-se cada vez mais viável e necessário. Marc parece pronto a seguir o caminho que começa a ser traçado pelo esboço de seu desejo.

\section{ESCOLA EXPERIMENTAL DE BONNEUIL: UM LUGAR PARA SER}

O tratamento realizado por Bonneuil já permitiu muitas crianças autistas que passaram por lá - e que continuam a passar - a encontrar um lugar como sujeito no seio de suas famílias e da sociedade. Com a exposição do caso de Marc, podemos constatar que Bonneuil não altera seu funcionamento "estourado" de 


\section{Escola de Bonneuil: estudo sobre o tratamento "estourado" do autismo}

acordo com as dificuldades de cada criança. Ele é instituído para todos. Assim, mesmo manifestando uma forte repulsa ao trabalho coletivo, Marc foi inserido em uma dinâmica de "idas e vindas" que o fez quebrar regras, abrir-se para o mundo e cruzar pessoas diferentes, em momentos diferentes, vivenciando encontros mundanos.

Vale ressaltar que, apesar da aparente incompatibilidade do "estouro" de Bonneuil e da necessidade de imutabilidade do sujeito autista, essa iniciativa não deve ser interpretada como uma negligência. Muito pelo contrário, estas crianças são acolhidas pela equipe, a qual se dispõe a um encontro verdadeiro. Elas são convidadas a expor suas condições psíquicas, distanciando-as de uma "montanha" de dossiês médicos contendo etiquetas nosológicas excludentes. A essência dessa prática antipsiquiátrica e antinosológica permite que estas crianças possam inscrever um novo destino e fugir das fórmulas pré-concebidas e cristalizadoras da doença mental.

Destaca-se, assim, outra importante estratégia terapêutica de Bonneuil que não foi mencionada no início do nosso trabalho, mas que, todavia, o atravessa: a singularidade - como esboço de uma subjetividade - onde cada criança é reconhecida e levada em consideração. Na verdade, Bonneuil oferece um acompanhamento ímpar, a partir do qual cada aluno tem um calendário escolar e um projeto educacional desenvolvido com base em suas capacidades, necessidades e, sobretudo, nos seus desejos. Lá, cada um traça um caminho específico. No caso das crianças autistas, procura-se extraí-las do caos de sensações através do uso da linguagem. Este é o primeiro passo a ser traçado em direção à experiência subjetiva.

Embora essa prática possa parecer ameaçadora para o autista, Bonneuil continua a proclamar a necessidade de expor essas crianças aos encontros, mundo afora, a fim de evitar toda forma de isolamento e de aprisionamento psíquico. Assim, a escola as lança numa busca por autonomia que será elaborada de acordo com o desejo emergente de cada uma. Vale ressaltar que esse caminho é seguido "de mãos dadas" com o adulto, outra forma de falar de um verdadeiro trabalho de apoio psíquico. Em outras palavras, esse dispositivo clínico arrisca efeitos subjetivantes, colocando-se na contramão de uma proposta de estabilidade cotidiana e pragmática.

Para finalizar nossa reflexão, é preciso deixar claro que o presente artigo não teve a pretensão de descrever um dispositivo ideal para o autismo, mas, sim, de relembrar o que dele nos parece pertinente, ainda hoje.

Recebido em: 2 de junho de 2015. Aprovado em: 5 de novembro de 2015.

\section{REFERÊNCIAS}

AMERICAN PSYCHIATRIC ASSOCIATION. Diagnostic and statistical manual of mental disorders (DSMII). Washington: APA Press, 1972.

Diagnostic and statistical manual of mental disorders (DSM-III). Washington: APA Press, 1980.

Diagnostic and statistical manual of mental disorders (DSM-V). Washington: APA Press, 2013.

BERGÈS, J.; BALBO, G. O jogo de posições da mãe e da criança: ensaio sobre o transitivismo. Porto Alegre: CMC, 2002.

BERNARDINO, L. M. F. De uma instituição ideal a uma prática possível: efeitos de um (bom) encontro. Estilos Clin., v.3, n. 4, 1998, p. 80-85.

BETTELHEIM, B. A Fortaleza Vazia (1967). São Paulo: Martins Fontes, 1987.

de LAJONQUIERE, L. A psicanálise, a educação e a escola de Bonneuil. A (à) lembrança de Maud Mannoni. Estilos Clin., v. 3, n. 4, 1998, p. 65-79.

DELION, P.; GOLSE, B. (orgs.) Autisme: état des lieux et horizons. Ramonville Saint-Agne: Érès, 2006.

DUCHE, D-J. Histoire de la psychiatrie de l'enfant. Paris: Presses Universitaires de France, 1990.

GEOFFROY, M. A. A “Instituição Estourada” como “jogo do fort-da” - De Jacques Lacan ao conceito de instituição estouradada escola experimental de Bonneuil. Estilos Clin., v. 17, n. 9, 2004.

HOCHMANN, J. L'histoire de l'Autisme. Paris: O. Jacob, 2009. 
KANNER, L. Autistic disturbances of affective contact. Nervous Child, v. 2, 1943, p. 217-250.

KANNER, L.; EISENBERG, L. Early infantile autism. J Orthopsychiat., v. 26, 1956, p. 55-65.

KLEIN, M. A importância da formação de símbolos no desenvolvimento do ego (1930). In: Amor, culpa e reparação e outros trabalhos. Trad. A. Cardoso. Rio de Janeiro: Imago, 1966.

KUPFER, M. C. Desventuras de uma estagiária em Bonneuil. Estilos Clin., v. 3, n. 4, 1998, p. 107-111.

LACAN, J. Os escritos técnicos de Freud (1953-1954). Rio de Janeiro: Zahar, 1983. (O seminário, 1).

LAZNIK, M-C. (2000) La théorie lacanienne de la pulsion permettrait de faire avancer la recherche sur l'autisme. La célibataire, v. 5, 2000, p. 67-78.

Pré-Aut: une recherche et une clinique du très précoce. Contraste, v. 25, 2006.

LEDOUX, M. Conceptions psychanalytiques de la psychose infantile. Paris: PUF, 1984.

LEFORT, R.; LEFORT, R. La distinction de l'autisme. Paris: Seuil, 2003.

LOBO, L. F. Os infames da história. Pobres, escravos e deficientes no Brasil. Rio de Janeiro: Lamparina, 2008.

MAESTRO, S.; MURATORI, F. Les films familiaux. In: DELION, P.; GOLSE, B. (orgs.). Autisme: etats des lieux et horizons. Ramonville Saint-Agne: Eres, 2006.

MALEVAL, J-C. L'autista et sa voix. Paris: Seuil, 2009.

MANNONI, M. A criança retardada e sua mãe (1964). São Paulo: Martins Fontes, 1981.

A criança, sua doença e os outros (1967). Rio de Janeiro: Zahar, 1971.

. A primeira entrevista em psicanálise (1965). Rio de Janeiro: Campos, 1980.

Bonneuil seize ans après: comment échapper aux destins programés de l’Etat-Providence. Paris: Denoël, 1986

Educação impossível (1973). Rio de Janeiro: Zahar, 1977.

O psiquiatra, seu "louco" e a psicanálise (1970). Rio de Janeiro: Zahar, 1989.

. Un lieu pour vivre: les enfants de Bonneuil, leurs parents et l'équipe des «soignants». Paris: Seuil, 1976.

MESQUITA, M. Aux frontières de l'autisme et de la psychose infantile: La place d'importance de la psychanalyse dans le champ de la psychiatrie de l'enfant. Tese de doutorado. Curso de Pós-graduação em Psicologia, Universidade Paris 13, Villetaneuse, França. 2012.

PLANTET, J. Bonneuil, un héritage pour demain. Le lien social, v. 1050, 2012.

POTTER, H. Schizophrenia in children. American Journal of Psychiatry, v. 12, 1933, p. 1253-1270.

SCHOPLER, E., BRENM, S. S., KINSBOURNE, M.; REICHLER, R. Effects of treatment structure on development in autistic children. Arch. Gen. Psychiatry, v. 24, n. 5, 1971, p. 415-421.

SCHOPLER, E.; REICHLER, R. Parents as co-therapists in the treatment of psychotic children. Journal of autism and childhood schizophrenia, v. 1, n. 1, 1971, p. 87-102.

VANIER, A. Psychanalyse et antipsychiatrie. Topique, v. 88, 2004, p. 79-85.

WINNICOTT, D. (1968). La schizophrénie infantile en termes d'échec d'adaptation. Recherches, v. 2, 1968, p. 27-31.

\section{Mirka Mesquita}

mirkamesquita@hotmail.com

Karla Patrícia Holanda Martins

kphm@uol.com.br 